\title{
Advanced cognitive impairment among older nursing home residents
}

\author{
Tadeja Gracner ${ }^{1 *}$ (D), Patricia W. Stone ${ }^{2}$, Mansi Agarwal ${ }^{3}$, Mark Sorbero ${ }^{4}$, Susan L Mitchell ${ }^{5,6}$ and Andrew W. Dick
}

\begin{abstract}
Background: Though work has been done studying nursing home $(\mathrm{NH})$ residents with either advanced Alzheimer's disease (AD) or Alzheimer's disease related dementia (ADRD), none have distinguished between them; even though their clinical features affecting survival are different. In this study, we compared mortality risk factors and survival between $\mathrm{NH}$ residents with advanced $\mathrm{AD}$ and those with advanced ADRD.

Methods: This is a retrospective observational study, in which we examined a sample of 34,493 U.S. NH residents aged 65 and over in the Minimum Data Set (2011-2013). Incident assessment of advanced disease was defined as the first MDS assessment with severe cognitive impairment (Cognitive Functional Score equals to 4) and diagnoses of AD or ADRD. Demographics, functional limitations, and comorbidities were evaluated as mortality risk factors using Cox models. Survival was characterized with Kaplan-Maier functions.

Results: Of those with advanced cognitive impairment, $35 \%$ had AD and $65 \%$ ADRD. At the incident assessment of advanced disease, those with AD had better health compared to those with ADRD. Mortality risk factors were similar between groups (shortness of breath, difficulties eating, substantial weight-loss, diabetes mellitus, heart failure, chronic obstructive pulmonary disease, and pneumonia; all $p<0.01$ ). However, stroke and difficulty with transfer (for women) were significant mortality risk factors only for those with advanced AD. Urinary tract infection, and hypertension (for women) only were mortality risk factors for those with advanced ADRD. Median survival was significantly shorter for the advanced ADRD group (194 days) compared to the advanced AD group (300 days).
\end{abstract}

Conclusions: There were distinct mortality and survival patterns of $\mathrm{NH}$ residents with advanced AD and ADRD. This may help with care planning decisions regarding therapeutic and palliative care.

Keywords: Advanced cognitive impairment, End-of-Life, Alzheimer's disease, Dementia, Survival

\section{Background}

Alzheimer's disease (AD) and related dementias (ADRD) are the 6th leading cause of death in the United States (US) [1-3]. Unless another fatal illness intervenes, these diagnoses will progress to an advanced stage, ultimately resulting in death [4]. Approximately $70 \%$ of persons with AD or ADRD die in nursing homes (NHs) [5]. Accurately identifying a health state we refer to as advanced disease is therefore critical to providing optimal

\footnotetext{
* Correspondence: tgracner@rand.org

'RAND Corporation, 1776 Main Street, Santa Monica, CA 90401, USA

Full list of author information is available at the end of the article
}

care; as is differentiating mortality risk factors and survival patterns across groups because underlying causes of decline are heterogeneous.

Although $\mathrm{AD}$ is the most recognized form of dementia, its clinical features and cognitive impairments affecting survival are different from ADRD, which includes dementia with Lewy bodies (DLB), frontotemporal dementia, Parkinson's, mixed dementia, as well as vascular or multi-infarct dementia [6-8]. Researchers have found that ADRD patients have shorter survival compared to those with $A D$ [9-11], that their survival depends on sex, cognitive level, neuropathology [2, 3, 12-14], and that $\mathrm{AD}$ and $\mathrm{ADRD}$ patients differ in their co-existing

(c) The Author(s). 2021 Open Access This article is licensed under a Creative Commons Attribution 4.0 International License, which permits use, sharing, adaptation, distribution and reproduction in any medium or format, as long as you give appropriate credit to the original author(s) and the source, provide a link to the Creative Commons licence, and indicate if changes were made. The images or other third party material in this article are included in the article's Creative Commons licence, unless indicated otherwise in a credit line to the material. If material is not included in the article's Creative Commons licence and your intended use is not permitted by statutory regulation or exceeds the permitted use, you will need to obtain permission directly from the copyright holder. To view a copy of this licence, visit http://creativecommons.org/licenses/by/4.0/ The Creative Commons Public Domain Dedication waiver (http://creativecommons.org/publicdomain/zero/1.0/) applies to the data made available in this article, unless otherwise stated in a credit line to the data. 
functional impairments or co-morbidities $[10,15,16]$. For instance, eating difficulties and related weight-loss are common complications in patients with $\mathrm{AD}$, and are a significant predictor of end of life [14, 17]. On the other hand, for patients with ADRD such as DLB, walking and fall-related injuries are among the largest mortality risks [18, 19], whereas these risks are not as substantial for patients with AD. For some other types of ADRD, such as vascular dementia, hypertension, diabetes, and stroke remain the most important mortality risk factors [20, 21]. Finally, evidence shows that disease progression is more rapid for those with ADRD than for patients with $\mathrm{AD}[22,23]$.

However, the previous work studying AD and especially ADRD does not focus on its most severe and advanced stage. Though work has been done studying survival and mortality risks in people with either advanced $\mathrm{AD}$ or ADRD [3, 11-13, 18, 19, 24], less is known about whether residents with advanced $A D$ differ from those with advanced ADRD in their mortality risk factors and survival patterns $[14,25,26]$. Lack of prognosticators across $A D$ and ADRD may thus fail to recognize dementia as a terminal illness for these patients.

Early identification of when $\mathrm{NH}$ residents with either AD or ADRD enter the stage of advanced cognitive impairment may improve end of life care. Though previous researchers have used the routinely collected Minimum Data Set (MDS) to identify residents with advanced cognitive impairment [27], none have distinguished between $\mathrm{AD}$ and ADRD [28]. Using routine MDS assessments, our goal was to identify incident advanced cognitive impairment as observed in MDS and evaluate the differences in survival and mortality risk factors for those with advanced AD and those with advanced ADRD.

\section{Methods}

This is a retrospective cohort study of a nationally representative sample of US NH residents with advanced AD or ADRD between 2011 and 2013. The Institutional Review Boards approved this study.

\section{Data source}

We used data from the 2011 to 2013 MDS 3.0, which is a comprehensive, standardized resident screening and assessment tool, federally mandated for use in all licensed US NHs. We included the routine assessments for $\mathrm{NH}$ residents that are required upon admission (or readmission), quarterly thereafter, and at any time there is a significant change in health status. We also included assessments that are completed at or around 5, 14, 30, 60 , and 90 days following admission or readmission from hospital. We obtained Vital Status data linked to individual MDS identifiers, providing date of death for each NH resident through November 2016.

\section{Study population and measures}

We started with a random sample of 1 million $\mathrm{NH}$ residents aged 65 and above who had at least one quarterly or annual assessment from 2011 to 2013. From these, we identified residents for whom we observed the incident advance cognitive impairment assessment in MDS, defined as the first assessment on which the criteria were satisfied, with at least one prior quarterly, annual, or admission assessment in which they were not satisfied. These criteria required a diagnosis of AD (MDS item I4200) and/or a diagnosis of ADRD. For ADRD, we use the MDS item I4800, which refers to Non-Alzheimer's dementia, including DLB, frontotemporal dementia, Parkinson's or Creutzfeldt-Jakob disease, mixed dementia, or vascular or multi-infarct dementia. In addition, a cognitive function score (CFS) equal to 4 (i.e., severely impaired) had to be present on the same assessment $[29,30]$. We did not use ICD9 for any diagnoses. How CFS is obtained has been explained elsewhere [30].

In our data, most of the $\mathrm{NH}$ residents who were diagnosed with dementia had only ADRD diagnoses (65\%), but a significant fraction had both ADRD and AD diagnoses $(21 \%)$, and only $14 \%$ had $\mathrm{AD}$ diagoses only. To explore how different or similar their survival patterns were, we estimated survival and hazard functions for each of these three mutually exclusive groups. Residents with $\mathrm{AD}$ and those with $\mathrm{AD}$ and ADRD exhibited similar survival patterns, but different patterns from those who were diagnosed only with ADRD (see the Supplement, eFigure 1). Guided by these empirical patterns, we divided our sample into two mutually exclusive groups: those with $\mathrm{AD}$ (with or without an ADRD diagnosis) and those with ADRD (without an AD diagnosis), hereafter referred to as $A D$ and $A D R D$, respectively. Like others, we assumed that AD and ADRD were considered permanent once diagnosed [14, 29]. To protect against data errors and false positives, we required advanced cognitive impairment to be present on at least two assessments unless there were only two or fewer assessments remaining before death (in which case we required only one positive assessment).

\section{Predictors of survival}

Based on the literature, demographics, functional status, comorbidities, and other health conditions were selected a priori as potential predictors of survival $[2,10,14-16$, $18,19,26,31-33]$. Residents' demographic characteristics included age $(60-74,75-84,85-94$, and 95+), sex, marital status (yes/no), and race/ethnicity (American Indian or Alaskan, Asian, African American, Hispanic, Native Hawaiian/Pacific Islander, Caucasian). Functional status was measured using Activities of Daily Living (ADL) items: eating, bathing, locomotion, bed mobility, walking, toileting, transferring, hygiene, or dressing. A 
score $\geq 3$ indicated difficulty with the ADL. Comorbidities at the advanced cognitive impairment incident assessment included indicators for diabetes mellitus, congestive heart failure, hypertension, chronic obstructive pulmonary disease (COPD), and stroke, as well as depression. Other health conditions included bowel or urinary incontinence (rarely or never vs. occasionally, frequently, or always), experiencing shortness of breath sitting or lying, pneumonia or other respiratory tract infection, urinary tract infection (UTI) in the previous 30 days, hip fracture in the prior 180 days, and weight-loss of more than $5 \%$ in the last month or more than $10 \%$ in the last 6 months.

\section{Statistical analysis}

Descriptive analyses were conducted to identify differences in the predictors of survival between $\mathrm{AD}$ and ADRD residents with advanced cognitive illness using two-sided t-tests. For $\mathrm{NH}$ residents whose death date we observed in the follow-up period, survival was defined as the duration between their incident advanced disease assessment and date of death. Residents that survived until the end of the follow-up period were treated as censored. We estimated Cox multivariable survival models with nonparametric baseline survival functions stratified by sex for both AD and ADRD residents. We specified the models conditional on the predictor variables listed above and measured on the assessment identifying incident advanced cognitive impairment, as well as interactions between $\mathrm{AD}$ and ADRD and selected predictors. We assessed the proportional hazards assumption by examining log-log survival plots. Kaplan-Maier survival functions were developed separately by AD and ADRD as well as by sex. We calculated 25th, 50th and 75th percentiles in survival time (days) along with the probability of survival at the end of year 1, 2 and 3 since the onset of advanced cognitive impairment, both in total and by sex. All statistical analyses were performed using STATA MP, version 16 [34].

\section{Results}

There were 34,493 (3.5\%) residents that met eligibility criteria for advanced cognitive impairment; among those, $35.0 \%$ had AD and $65.0 \%$ had ADRD. Most of the $\mathrm{NH}$ residents in our sample (i.e., with incident advanced cognitive impairment) died before the end of follow-up with only $11.9 \%$ of the survival times censored.

Table 1 presents the comparison of $\mathrm{AD}$ and ADRD groups. About $65 \%$ percent were female, and about $80 \%$ were white non-Hispanic. All differences reported below are statistically significant at $p<0.01$. At the onset of advanced cognitive impairment, $\mathrm{NH}$ residents diagnosed with ADRD had more comorbidities than those with
$\mathrm{AD}$, such as diabetes mellitus (28.88 and $24.28 \%$, respectively), stroke (21.57 and $12.48 \%$, respectively), and hypertension (74.83 and $71.12 \%$, respectively). NH residents with ADRD were also more likely to experience difficulties with ADLs, such as eating (66.35 and $63.76 \%$, respectively), walking (88.32 and $82.22 \%$, respectively), and locomotion (86.34 and $79.67 \%$, respectively), and to have experienced heart failure $(19.44$ and $15.16 \%$, respectively) and shortness of breath in the 7 days since the last MDS assessment (11.83 and 8.16\%, respectively). However, residents with ADRD were less likely than those with $\mathrm{AD}$ to experience depressive symptoms (41.52 and $45.64 \%$, respectively).

Table 2 presents the Cox survival regressions. Most predictors of death had similar hazard ratios (HR) for both $\mathrm{AD}$ and ADRD. In both $\mathrm{AD}$ and ADRD residents with advanced cognitive impairment, the following comorbidities were associated with greater mortality risk: diabetes mellitus (HR 1.11 and 1.12, respectively), heart failure (HR 1.24 and 1.26, respectively) and COPD (HR 1.13 for both). Mortality risks in AD and ADRD residents with advanced cognitive illness were highest for those who were experiencing shortness of breath (HR 1.65 and 1.54, respectively), substantial weight-loss (HR 1.31 and 1.35 , respectively) or difficulty eating (HR 1.28 and 1.31, respectively) and pneumonia (HR 1.34 and 1.22 , respectively). Difficulty with walking and bed mobility were both significant mortality risk factors for ADRD residents (HR 1.14 $(p<0.01)$ and $1.90(p<0.05)$, respectively) only. Experiencing stroke and difficulty with locomotion were both significant mortality risk factors for $\mathrm{AD}$ residents (HR $1.08 \quad(p<0.05)$ for both). Among the predictors, only having a stroke and being older than 95 years were significantly different between $\mathrm{AD}$ and $\mathrm{ADRD}$ residents.

There were differences in mortality risk factors for both AD and ADRD within sex (see Table 3). The largest mortality risk factors for women regardless of $\mathrm{AD}$ or ADRD diagnoses were shortness of breath, heart failure, difficulty eating, and weight-loss (HR 1.70, 1.26, 1.26, 1.31 for ACI-AD and HR 1.51, 1.27, 1.34 and 1.34, for ACI-ADRD; all $p<0.01)$. Stroke and difficulty with transfer were also significant mortality risk factors for women with $\mathrm{AD}$ (HR 1.16 and 1.20, respectively, both $p<0.01$ ). Difficulty with walking (HR 1.17, $p=0.01$ ), hypertension and urinary incontinence (HR 1.06 and 1.12 , respectively, both $p<0.05)$ were significant mortality risk factors for women with ADRD. For men, diabetes mellitus, heart failure, difficulties with bed mobility or eating, and substantial weight-loss were significant risk factors regardless for both AD and ADRD residents (HR 1.10, 1.19, 1.37, 1.33, 1.21, 1.48, and 1.28, respectively, for $\mathrm{AD}$; $\mathrm{HR} 1.12,1.26,1.31,1.16,1.16,1.55$, and 1.33, respectively for ADRD, all $p<0.05$ ); and COPD 
Table 1 Descriptive Statistics of NH residents with advanced cognitive impairment at the incident assessment

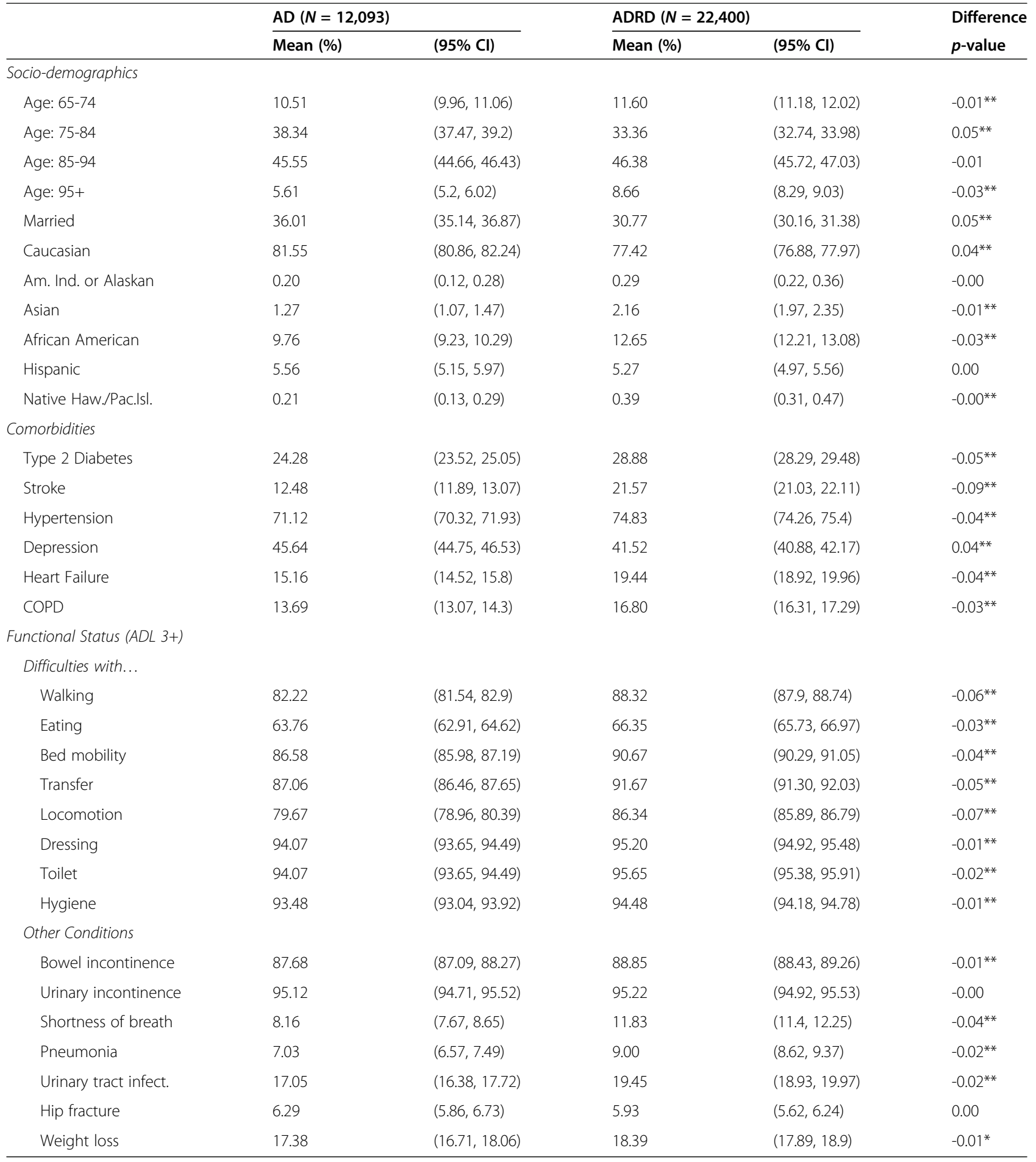

Note: Mean and standard deviation reported for a list of covariates at the time of the incident advanced cognitive impairment assessment. *, and **, describe statistically significant difference between means at a $p$-value smaller or equal to 0.05 and 0.01 , respectively, computed by conducting a two-sided equality of means t-test between advanced $A D$ and $A D R D$ groups

Abbreviations: $A D$ Alzheimer's disease, $A D R D$ related dementias, $A D L$ activities of daily living, $C O P D$ chronic obstructive pulmonary disease, $N H$ nursing home 
Table 2 Mortality risk factor estimates using cox regression models for $\mathrm{NH}$ residents with advanced cognitive impairment

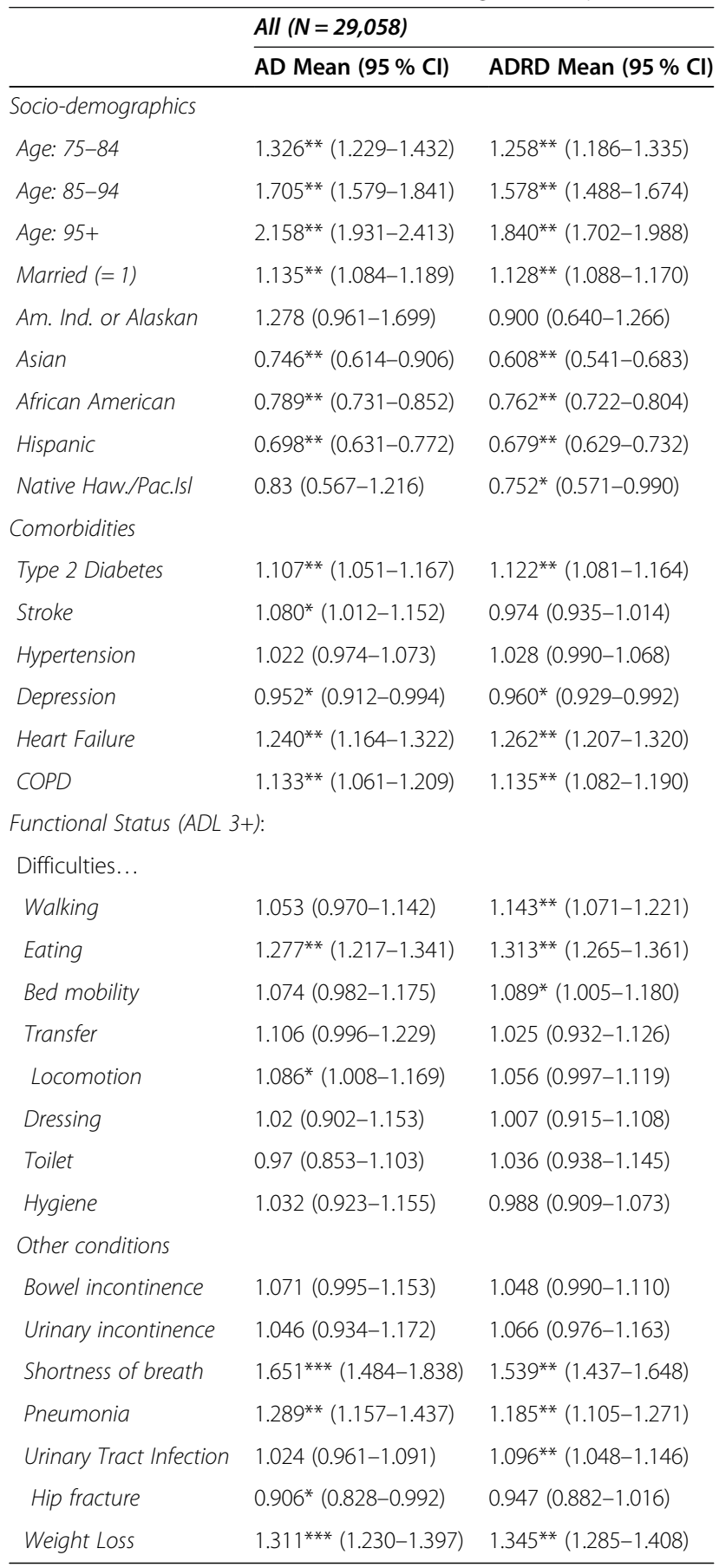

Note: ${ }^{*}$, and ${ }^{* *}$ denotes coefficient significance at the 0.05 , or 0.01 levels, respectively. Robust standard errors reported in brackets. Weight loss is recorded if the resident lost $>5 \%$ of his or her weight last month or $>10 \%$ in 6 months

Abbreviations: $A D$ Alzheimer's disease, $A D R D$ related dementias, $A D L$ activities of daily living, $C O P D$ chronic obstructive pulmonary disease, $\mathrm{NH}$ nursing home was a significant risk factor for men with ADRD (HR $1.10, p<0.05)$ but not for men with AD.

As presented in Fig. 1; Table 4, the median survival times were on average 300 (CI95\% 286 to 315) and 194 (CI95\% 186 to 202) days for AD and ADRD residents, respectively. By the end of year 1, the probability of survival for NH residents was $46.3 \%$ (CI95\% 45.4 to 47.2 ), and $39.0 \%$ (CI95\% 39.4 to 39.7) for those with $\mathrm{AD}$ and ADRD, respectively. Absolute differences in survival rates between disease groups decreased with time, and by year 3 the rate of survival for $\mathrm{NH}$ residents with $\mathrm{AD}$ was $19.9 \%$ (CI95\% 19.2 to 20.7 ) compared to $16.6 \%$ (C195\% 16.1 to 17.1) for those with ADRD. Men had substantially lower survival rates than women throughout the first three years regardless of the dementia diagnosis. For instance, by year 3 , the survival rate for women with $\mathrm{AD}$ was $23.5 \%$ (CI95\% 22.6 to 24.4) compared to $19.2 \%$ (CI95\% 18.6 to 19.9) for those with ADRD. For men, the survival rate at year 3 was around $12 \%$ regardless of dementia diagnosis.

\section{Discussion}

Significant differences were found in health status at the incident advanced cognitive impairment, as well as in survival patterns. We find that among $\mathrm{NH}$ residents with advanced cognitive impairment, on average, those with ADRD are of worse health compared to those with AD at their incident assessment of advanced cognitive impairment as observed in MDS. This may be largely because ADRD is a heterogenous collection of conditions that likely have different underlying causes, comorbidities and the rate of disease progression, but it may also be that ADRD is diagnosed later in life than $\mathrm{AD}$, particularly in a $\mathrm{NH}$ environment [13, 14, 20, 23]. On average, residents with ADRD are more likely than those with $\mathrm{AD}$ to be older than 85 at the incident advanced cognitive impairment assessment.

On the other hand, most of mortality risk factors were similar across groups. This highlights an important fact which is that regardless of the type of dementia, issues that residents, as well as families and caregivers are confronted with at the end of one's life are similar. For both, $\mathrm{AD}$ and ADRD residents with advanced cognitive impairment, the largest mortality risk factors were shortness of breath, pneumonia, weight loss and difficulties with eating; and these were similar for both, men and women. Stroke and difficulty with locomotion were a significant risk factor for women with AD only, but difficulty with bed mobility, walking and UTI were significant risk factors for residents with ADRD, regardless of sex. These results are consistent with the literature. For instance, eating difficulties and related weight-loss are common complications in patients with $\mathrm{AD}$, and are a significant predictor of end of life $[14,17]$. On the other 
Table 3 Mortality risk factor estimates using cox regression models for $\mathrm{NH}$ residents with advanced cognitive impairment by sex

\begin{tabular}{|c|c|c|c|c|}
\hline & \multicolumn{2}{|l|}{ WOMEN $(N=19,575)$} & \multicolumn{2}{|l|}{$\operatorname{MEN}(N=9,483)$} \\
\hline & AD Mean $(95 \% \mathrm{Cl})$ & ADRD Mean $(95 \% \mathrm{Cl})$ & AD Mean $(95 \% \mathrm{Cl})$ & ADRD Mean $(95 \% \mathrm{Cl})$ \\
\hline \multicolumn{5}{|l|}{ Socio-demographics } \\
\hline Age: $75-84$ & $1.270^{* *}(1.147-1.406)$ & $1.296^{* *}(1.192-1.409)$ & $1.447^{* *}(1.288-1.627)$ & $1.290^{* *}(1.184-1.406)$ \\
\hline Age: 85-94 & $1.667^{* *}(1.507-1.843)$ & $1.644^{* *}(1.514-1.784)$ & $1.885^{* *}(1.668-2.129)$ & $1.675^{* *}(1.533-1.831)$ \\
\hline Age: $95+$ & $2.170^{* *}(1.900-2.478)$ & $1.966^{* *}(1.782-2.170)$ & $2.486^{* *}(1.931-3.202)$ & $1.994^{* *}(1.723-2.308)$ \\
\hline Married (=1) & $0.999(0.938-1.064)$ & $0.976(0.927-1.028)$ & $0.981(0.907-1.061)$ & $1.042(0.985-1.103)$ \\
\hline Am. Ind. or Alaskan & $1.525^{* *}(1.155-2.013)$ & $1.082(0.688-1.700)$ & $0.89(0.472-1.678)$ & $0.654(0.388-1.103)$ \\
\hline Asian & $0.82(0.637-1.055)$ & $0.642^{* *}(0.559-0.738)$ & $0.601 * *(0.442-0.818)$ & $0.550^{* *}(0.445-0.679)$ \\
\hline African American & $0.802^{* *}(0.728-0.882)$ & $0.731^{* *}(0.682-0.783)$ & $0.716^{* *}(0.627-0.816)$ & $0.781^{* *}(0.717-0.851)$ \\
\hline Hispanic & $0.719^{* *}(0.633-0.816)$ & $0.641^{* *}(0.579-0.709)$ & $0.626^{* *}(0.530-0.739)$ & $0.699^{* *}(0.624-0.784)$ \\
\hline Native Haw./Pac.|sl & $0.822(0.540-1.252)$ & $0.721(0.518-1.004)$ & $0.862(0.370-2.006)$ & $0.738(0.455-1.197)$ \\
\hline \multicolumn{5}{|l|}{ Chronic conditions } \\
\hline Type 2 Diabetes & $1.070 *(1.001-1.144)$ & $1.103^{* *}(1.053-1.156)$ & $1.102^{*}(1.013-1.200)$ & $1.124^{* *}(1.055-1.197)$ \\
\hline Stroke & $1.159^{* *}(1.070-1.255)$ & $0.984(0.936-1.035)$ & $0.916(0.819-1.025)$ & $0.932 * *(0.871-0.998)$ \\
\hline Hypertension & $1.037(0.977-1.101)$ & $1.060^{*}(1.011-1.113)$ & $1.013(0.933-1.101)$ & $0.998(0.938-1.063)$ \\
\hline Depression & $0.974(0.924-1.027)$ & $0.991(0.952-1.032)$ & $0.968(0.898-1.044)$ & 0.950 (0.897-1.006) \\
\hline Heart Failure & $1.257^{* *}(1.164-1.358)$ & $1.267^{* *}(1.199-1.337)$ & $1.189 * *(1.062-1.332)$ & $1.255^{* *}(1.160-1.359)$ \\
\hline COPD & $1.124^{* *}(1.035-1.220)$ & $1.129 * *(1.064-1.199)$ & $1.090(0.977-1.216)$ & $1.097^{*}(1.016-1.185)$ \\
\hline \multicolumn{5}{|l|}{ Functional status (ADL 3+) } \\
\hline \multicolumn{5}{|l|}{ Difficulties... } \\
\hline Walking & $1.073(0.971-1.186)$ & $1.169 * *(1.077-1.269)$ & $1.036(0.902-1.189)$ & $1.093(0.984-1.214)$ \\
\hline Eating & $1.260^{* *}(1.188-1.338)$ & $1.340 * *(1.281-1.402)$ & $1.370 * *(1.259-1.491)$ & $1.314^{* *}(1.234-1.399)$ \\
\hline Bed mobility & $0.974(0.872-1.087)$ & $1.073(0.971-1.186)$ & $1.331^{* *}(1.139-1.557)$ & $1.163^{*}(1.020-1.327)$ \\
\hline Transfer & $1.199 * *(1.051-1.367)$ & $1.01(0.897-1.137)$ & $0.922(0.768-1.107)$ & $1.032(0.884-1.205)$ \\
\hline Locomotion & $1.092(0.997-1.195)$ & $1.091 *(1.017-1.172)$ & $1.123(0.987-1.278)$ & 1.031 (0.937-1.134) \\
\hline Dressing & $0.981(0.848-1.134)$ & $1.015(0.903-1.141)$ & $1.082(0.847-1.382)$ & $1.004(0.850-1.185)$ \\
\hline Toilet & $0.958(0.822-1.116)$ & $1.031(0.910-1.167)$ & $0.931(0.725-1.196)$ & $1.046(0.887-1.233)$ \\
\hline Hygiene & $1.073(0.937-1.230)$ & $0.948(0.857-1.049)$ & $0.929(0.757-1.140)$ & $1.026(0.887-1.187)$ \\
\hline \multicolumn{5}{|l|}{ Other conditions } \\
\hline Bowel incontinence & $1.078(0.986-1.179)$ & $1.009(0.941-1.082)$ & $1.005(0.886-1.141)$ & 1.089 (0.986-1.202) \\
\hline Urinary incontinence & $1.062(0.926-1.217)$ & $1.121^{*}(1.007-1.248)$ & $1.132(0.917-1.397)$ & $0.986(0.850-1.145)$ \\
\hline Shortness of breath & $1.699 * *(1.480-1.949)$ & $1.509^{* *}(1.382-1.647)$ & $1.481^{* *}(1.245-1.762)$ & $1.553^{* *}(1.392-1.732)$ \\
\hline Pneumonia & $1.259^{* *}(1.088-1.457)$ & $1.108^{*}(1.006-1.221)$ & $1.210^{*}(1.027-1.426)$ & $1.163^{* *}(1.052-1.285)$ \\
\hline Urinary Tract Infection & $1.051(0.977-1.131)$ & $1.119^{* *}(1.062-1.179)$ & $1.1(0.965-1.254)$ & $1.170^{* *}(1.071-1.277)$ \\
\hline Hip fracture & $0.961(0.864-1.068)$ & $0.945(0.870-1.026)$ & $0.797^{*}(0.665-0.956)$ & $1.034(0.901-1.187)$ \\
\hline Weight Loss & $1.313^{* *}(1.216-1.417)$ & $1.340 * *(1.268-1.416)$ & $1.281^{* *}(1.143-1.437)$ & $1.331^{* *}(1.227-1.444)$ \\
\hline
\end{tabular}

Note: *, and ** denotes coefficient significance at the 0.05 , or 0.01 levels, respectively. Robust standard errors reported in brackets. Weight loss is recorded if the resident lost $>5 \%$ of his or her weight last month or $>10 \%$ in 6 months

Abbreviations: $A D$ Alzheimer's disease, $A D R D$ related dementias, $A D L$ activities of daily living, COPD chronic obstructive pulmonary disease, $N H$ nursing home

hand, for patients with ADRD such as DLB, walking and fall-related injuries were among the largest mortality risks, possibly because these patients displayed severe deficits in attention and visuospatial processing, whereas these were not as a substantial risk factors for patients with AD. Patients with Parkinson's disease, for instance, have been found to have increased risk for UTI due to voiding dysfunctions, but also more commonly experienced swallowing disorders leading to eating difficulties and significant weight-loss. An important difference that we identified between AD and ADRD with advanced disease compared to the existing evidence is that stroke 


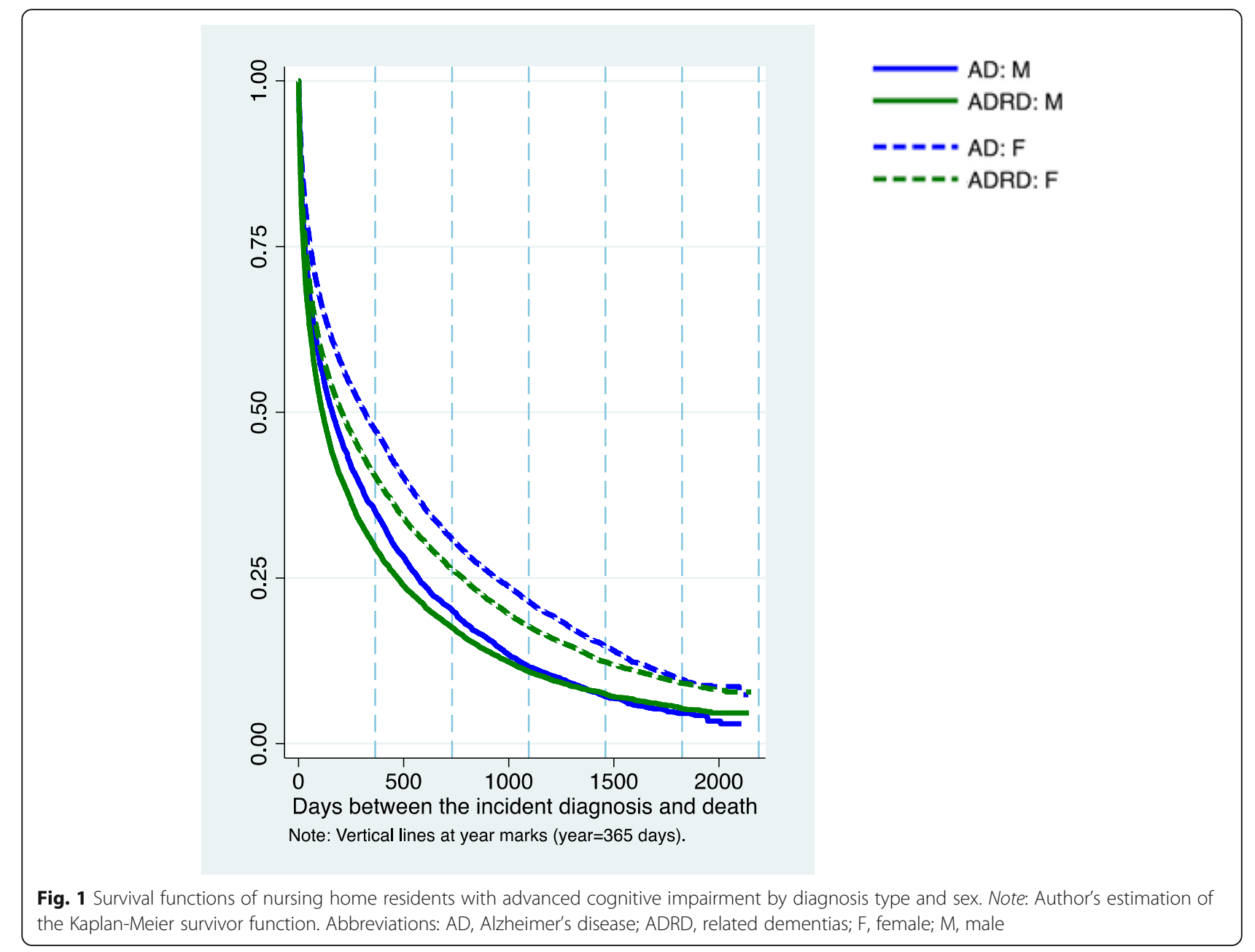

was mainly a significant risk factor for residents with $\mathrm{AD}$, especially women, and not for those with ADRD. Other evidence shows that for some other types of ADRD, such as vascular for dementia, hypertension, diabetes, and stroke remain the most important mortality risk factors [20, 35].

We also observe that mortality risk was consistently higher for whites (vs. non-whites) among residents diagnosed with either advanced AD or ADRD. Consistent with prior work, these results could be driven by a sample selection due to lower institutionalization rates among non-white residents with AD or ADRD [36]. Thus, non-white residents in our sample may have been wealthier and/or of better health than the white $\mathrm{NH}$ residents or average non-whites in community who we do not observe. There may be several unobserved mediators

Table 4 Survival probability and time since incident advanced cognitive impairment and death

\begin{tabular}{|c|c|c|c|c|c|c|c|}
\hline & \multirow[b]{2}{*}{$\mathbf{N}$} & \multicolumn{2}{|c|}{ Survival time in days (Cl $95 \%)$} & \multicolumn{2}{|c|}{ Probability of survival (\%) } & \multirow[b]{2}{*}{ Year 2 (Cl $95 \%)$} & \multirow[b]{2}{*}{ Year $3(\mathrm{Cl} 95 \%)$} \\
\hline & & $25 \%(\mathrm{Cl} 95 \%)$ & $50 \%(\mathrm{Cl} 95 \%)$ & $75 \%(C l 95 \%)$ & Year 1 (Cl $95 \%)$ & & \\
\hline$\overline{\mathrm{AD}}$ & 11,978 & $57(54,62)$ & $300(286,315)$ & $891(856,920)$ & $46.3(45.4,47.2)$ & $29.6(28.8,30.5)$ & $20.0(19.2,20.7)$ \\
\hline Women & 8,087 & $74(67,78)$ & $374(352,395)$ & $1031(996,1069)$ & $50.4(49.3,51.5)$ & $33.4(32.4,34.4)$ & $23.5(22.6,24.4)$ \\
\hline Men & 3,891 & $38(35,43)$ & $192(177,209)$ & $623(583,661)$ & $38.0(36.4,39.5)$ & $21.8(20.5,23.1)$ & $12.6(11.6,13.7)$ \\
\hline ADRD & 22,045 & $35(33,36)$ & $194(186,202)$ & $731(712,752)$ & $39.0(39.4,39.7)$ & $25.0(24.4,25.6)$ & $16.6(16.1,17.1)$ \\
\hline Women & 14,296 & $41(39,44)$ & $246(233,260)$ & $845(820,871)$ & $43.0(42.2,43.8)$ & $28.4(27.6,29.1)$ & $19.2(18.6,19.9)$ \\
\hline Men & 7,749 & $27(25,29)$ & $132(124,140)$ & $517(494,550)$ & $31.7(30.7,32.7)$ & $18.8(18.0,19.7)$ & $11.7(11.0,12.5)$ \\
\hline
\end{tabular}

Note: 25 th, 50th, and 75th percentile of survival times is obtained from S(t), the Kaplan-Meier estimate of the survivor function in Fig. 1. Survival time is reported in days. We report $95 \%$ confidence intervals in the brackets

Abbreviations: $A D$ Alzheimer's disease, $A D R D$ related dementias, $C l$ confidence interval 
in our data that could explain the differences in mortality risk, such as genetics, residents' socio-economic status, available resources, social networks, and social capital, as well as unobserved psychological stressors, discrimination, or access to medical or home or other care $[37,38]$.

Our results regarding survival are also supported by published literature. Researchers focusing on severe dementia (either AD or ADRD) have found that the median survival ranges from 2 days to 16 months but variability in survival time estimates is high [29, 31, 32]. Our survival rate estimates are similar to those found by Mitchell et al. 2010, who found that about $40 \%$ of patients with advanced dementia (either $\mathrm{AD}$ or ADRD) die within 1 year [29]. We add to this evidence by showing that there are differences in expected survival for those with AD compared to those with ADRD as identified in MDS, particularly in the first year after their onset of advanced cognitive impairment in which those with ADRD have higher mortality rates. Specifically, our estimated survival rate at year 1 is $46.3 \%$ for $\mathrm{AD}$ and $39 \%$ for ADRD residents (with $65 \%$ having ADRD). Like us, other investigators have found that the risk of mortality is smaller for patients with AD than for those with the ADRD but these studies have typically not limited their focus to those with advanced cognitive impairment and did not use MDS to differentiate the groups $[11,33]$. As others, we find lower survivals for men in both groups [11, 21, 29].

This study has limitations. First, diagnostics of the advanced cognitive impairment may be imprecise or under reported, particularly given the difficulty in diagnosing $\mathrm{AD}$ and ADRD. Though some of the advanced cognitive impairment cases may be missed [39], MDS data includes strict protocols about data reporting as well as the timing of assessments, and MDS 3.0 in particular has shown either excellent or very good reliability in assessments, their clinical relevance, and low rates of missing responses [40]; largely addressing concerns that the diagnoses are misclassified. Many have used similar measures to ours to identify cognitive impairments [14, 27, 29, 41, 42]. Second, ADRD arises from a variety of heterogeneous conditions, only some of which are identifiable (and imperfectly at that) in the MDS data. The extent to which each of those conditions gives rise to different patterns of survival in our data remains unknown, but the heterogeneity of ADRD may explain the different patterns of survival between $\mathrm{AD}$ and ADRD. Additionally, we cannot identify residents with a specific condition (e.g., DLB only) or exclude those usually not included in the ADRD definition (e.g., CreutzfeldtJakob disease). Third, an important goal of this paper was to define measures of advanced cognitive impairment that would be highly predictive of mortality, and although a large fraction of those identified with advanced disease died relatively quickly, the survival functions still have a long tail. Fourth, whether the first observed incident of advanced cognitive impairment in MDS is the actual time advanced disease is identified is unknown yet unavoidable due to data limitations. Because advanced cognitive impairment definitions require assessment data (complete with data on physical and cognitive limitations) we can only identify the first time the cognitive decline is observed in MDS for those who resided in NH before the disease progressed to advanced illness. As a result, we could identify the entire period of advanced cognitive impairment for only a fraction of those who reside in $\mathrm{NH}$. Though other clinical data may provide a more precise measure of the advanced cognitive impairment onset, our study utilizes MDS, which is a relatively easily accessible data source for other researchers. Since our focus is end of life, identifying the incident advanced cognitive impairment diagnosis as observed in the MDS is informative in that it provides a conservative estimate of survival for people with advanced disease once admitted to $\mathrm{NH}$. Finally, though we studied mortality risk factors, our data did not allow us to investigate pathways or mediators giving rise to these factors, such as genetics, residents' socioeconomic status, resources, social network or ties, as well as psychological stressors, discrimination, access to care or idiosyncratic behaviors [37, 38]. These questions are important to address in future research.

\section{Conclusions}

This study provided new evidence showing that routine MDS assessments may be used to differentiate between mortality risks and survival between $\mathrm{AD}$ and $\mathrm{ADRD}$ overall and by sex. Though mortality risks for NH residents with advanced ADRD and AD were largely similar, those with ADRD had worse health status on average and shorted survival from their observed incident of advanced cognitive impairment. Findings may inform future developments of risk tools used to identify end of life among $\mathrm{AD}$ and ADRD residents and help inform care planning decisions regarding therapeutic and palliative care.

\section{Abbreviations \\ AD: Alzheimer's disease; ADL: activities of daily living; ADRD: Alzheimer's related dementia; CFS: Cognitive function score; COPD: Chronic obstructive pulmonary disease; MDS: Minimum Data Set; NH: Nursing home; UTI: Urinary tract infections}

\section{Supplementary Information}

The online version contains supplementary material available at https://doi. org/10.1186/s12877-021-02336-1.

Additional file 1: eFigure 1: Survival and hazard function comparison for those diagnosed with advanced ADRD, AD, or both. 


\section{Acknowledgements}

We thank Catherine C. Cohen for helpful comments on earlier versions of this manuscript.

\section{Authors' contributions}

TG, MS, PS, and AD contributed to study design; TG, AD, MS, MA, SM, and PS contributed to management, analysis, and interpretation of data; as well as preparation, review, and approval of the manuscript. TG, MS and AD had full access to the data in the study. TG performed all data analyses under the supervision of AD. All authors have read and approved the manuscript.

\section{Funding}

This project was supported by the National Institute of Nursing Research (Grant R01NR013687). Dr. Mitchell is also supported by NIA K24AG033640. The funders had no role in study design, data collection and analysis, decision to publish, or preparation of the manuscript.

\section{Availability of data and materials}

The data that support the findings of this study are available from the Centers of Medicare and Medicaid but restrictions apply to the availability of these data, which were used under license for the current study, and so are not publicly available. Data are however available from the authors upon reasonable request and with permission of Centers of Medicare and Medicaid.

\section{Declarations}

\section{Ethics approval and consent to participate}

The Institutional Review Boards of The RAND Corporation (IRB 2017-0395CR03) and of Columbia University Medical Center (IRB-AAAR1564) approved this study. Data for this study was accessed under the DUA RSCH-201851931, approved by CMS.

\section{Consent for publication}

Not applicable.

\section{Competing interests}

The authors declare that they have no competing interests.

\section{Author details}

'RAND Corporation, 1776 Main Street, Santa Monica, CA 90401, USA. ${ }^{2}$ Center for Health Policy, Columbia University School of Nursing, 560 W. 168th St, New York, NY 10032, USA. ${ }^{3}$ Washington University School of Medicine, $660 \mathrm{~S}$ Euclid Ave, St.Louis, MO 63110, USA. ${ }^{4}$ RAND Corporation, 4570 Fifth Ave \#600, Pittsburgh, PA 15213, USA. ${ }^{5}$ Hebrew Senior Life Marcus Institute for Aging Research, Boston, MA, USA. ${ }^{6}$ Department of Medicine, Beth Israel Deaconess Medical Center, Boston, MA, USA. ${ }^{7}$ RAND Corporation, 20 Park Plaza \#920, Boston, MA 02116, USA.

\section{Received: 15 May 2020 Accepted: 11 June 2021}

\section{Published online: 23 June 2021}

\section{References}

1. National Institutes of Health. State-of-Science Conference Statement: Improving End-of-Life Care. National Institutes of Health. http://consensus. nih.gov/2004/2004EndOfLifeCareSOS024html.htm Published 2005. Accessed 20 March 2007.

2. Sampson EL, Candy B, Davis S, et al. Living and dying with advanced dementia: A prospective cohort study of symptoms, service use and care at the end of life. Palliat Med. 2018;32(3):668-81.

3. Wachterman M, Kiely DK, Mitchell SL. Reporting dementia on the death certificates of nursing home residents dying with end-stage dementia. JAMA. 2008;300(22):2608-10.

4. Mitchell SL, Black BS, Ersek M, et al. Advanced dementia: state of the art and priorities for the next decade. Ann Intern Med. 2012;156(1 Pt 1):45-51.

5. Mitchell SL, Teno JM, Miller SC, Mor V. A national study of the location of death for older persons with dementia. J Am Geriatr Soc. 2005;53(2):299-305.

6. NIA. Alzheimer's Disease \& Related Dementias. https://www.nia.nih.gov/hea Ith/alzheimers/related-dementias. Accessed 19 April 2021.
7. Montine TJ, Koroshetz WJ, Babcock D, et al. Recommendations of the Alzheimer's disease-related dementias conference. Neurology. 2014;83(9): 851-60.

8. NINDS. Focus on Alzheimer's Disease and Related Dementias. https://www. ninds.nih.gov/Current-Research/Focus-Disorders/Alzheimers-RelatedDementias. Accessed 19 April 2021.

9. Olichney JM, Galasko D, Salmon DP, et al. Cognitive decline is faster in Lewy body variant than in Alzheimer's disease. Neurology. 1998:51(2):351-7.

10. Williams MM, Xiong C, Morris JC, Galvin JE. Survival and mortality differences between dementia with Lewy bodies vs Alzheimer disease. Neurology. 2006;67(11):1935-41.

11. Garcia-Ptacek S, Farahmand B, Kareholt I, Religa D, Cuadrado ML, Eriksdotter M. Mortality risk after dementia diagnosis by dementia type and underlying factors: a cohort of 15,209 patients based on the Swedish Dementia Registry. J Alzheimers Dis. 2014;41(2):467-77.

12. Ahmed AA, Hays Cl, Liu B, et al. Predictors of in-hospital mortality among hospitalized nursing home residents: an analysis of the National Hospital Discharge Surveys 2005-2006. J Am Med Direct Assoc. 2010;11(1):52-8.

13. Alzheimer's A. 2018 Alzheimer's disease facts and figures. J Alzheimers Dementia. 2018;14(3):367-429.

14. Mitchell SL, Teno JM, Kiely DK, et al. The clinical course of advanced dementia. New England J Med. 2009;361(16):1529-38.

15. Bostrom F, Jonsson L, Minthon L, Londos E. Patients with Lewy body dementia use more resources than those with Alzheimer's disease. Int J Geriatr Psychiatry. 2007:22(8):713-9.

16. Bostrom F, Jonsson L, Minthon L, Londos E. Patients with dementia with lewy bodies have more impaired quality of life than patients with Alzheimer disease. Alzheimer Dis Assoc Disord. 2007;21(2):150-4.

17. Kai K, Hashimoto M, Amano K, Tanaka H, Fukuhara R, Ikeda M. Relationship between eating disturbance and dementia severity in patients with Alzheimer's disease. PLoS One. 2015;10(8):e0133666.

18. Institute of Medicine. Dying in America: Improving Quality and Honoring Individual Preferences Near the End of Life. Washington, D.C.: The National Academies Press; 2015

19. Kruse RL, Petroski GF, Mehr DR, Banaszak-Holl J, Intrator O. Activity of daily living trajectories surrounding acute hospitalization of long-stay nursing home residents. J Am Geriatr Soc. 2013;61(11):1909-18.

20. Desesquelles A, Demuru E, Salvatore MA, et al. Mortality from Alzheimer's disease, Parkinson's disease, and dementias in France and Italy: a comparison using the multiple cause-of-death approach. J Aging Health. 2014;26(2):283-315.

21. Molsa PK, Marttila RJ, Rinne UK. Long-term survival and predictors of mortality in Alzheimer's disease and multi-infarct dementia. Acta Neurol Scand. 1995;91(3):159-64.

22. Fereshtehnejad SM, Religa D, Westman E, Aarsland D, Lokk J, Eriksdotter M. Demography, diagnostics, and medication in dementia with Lewy bodies and Parkinson's disease with dementia: data from the Swedish Dementia Quality Registry (SveDem). Neuropsychiatr Dis Treat. 2013;9:927-35.

23. Hanyu H, Sato T, Hirao K, Kanetaka H, Sakurai H, Iwamoto T. Differences in clinical course between dementia with Lewy bodies and Alzheimer's disease. Eur J Neurol. 2009;16(2):212-7.

24. Boockvar KS, Gruber-Baldini AL, Burton L, Zimmerman S, May C, Magaziner J. Outcomes of infection in nursing home residents with and without early hospital transfer. J Am Geriatr Soc. 2005;53(4):590-6.

25. Teno JM, Gozalo P, Mitchell SL, Tyler D, Mor V. Survival after multiple hospitalizations for infections and dehydration in nursing home residents with advanced cognitive impairment. JAMA. 2013;310(3):319-20.

26. Wimo A, Guerchet M, Ali GC, et al. The worldwide costs of dementia 2015 and comparisons with 2010. Alzheimers Dement. 2017:13(1):1-7.

27. Mitchell SL, Morris JN, Park PS, Fries BE. Terminal care for persons with advanced dementia in the nursing home and home care settings. J Palliat Med. 2004;7(6):808-16

28. McCallion P, Hogan M, Santos FH, et al. Consensus statement of the International Summit on Intellectual Disability and Dementia related to endof-life care in advanced dementia. J Appl Res Intellect Disabil. 2017;30(6): $1160-4$

29. Mitchell SL, Miller SC, Teno JM, Davis RB, Shaffer ML. The advanced dementia prognostic tool: a risk score to estimate survival in nursing home residents with advanced dementia. J Pain Symptom Manage. 2010;40(5): $639-51$ 
30. Thomas KS, Dosa D, Wysocki A, Mor V. The Minimum Data Set 3.0 Cognitive Function Scale. Med Care. 2017;55(9):e68-72.

31. Hanrahan P, Luchins DJ. Feasible criteria for enrolling end-stage dementia patients in home hospice care. Hosp J. 1995;10(3):47-54.

32. Hicks KL, Rabins PV, Black BS. Predictors of mortality in nursing home residents with advanced dementia. Am J Alzheimers Dis Other Demen. 2010;25(5):439-45.

33. Price A, Farooq R, Yuan JM, Menon VB, Cardinal RN, O'Brien JT. Mortality in dementia with Lewy bodies compared with Alzheimer's dementia: a retrospective naturalistic cohort study. BMJ Open. 2017;7(11):e017504.

34. StataCorp LLC. Stata Statistical Software: Release $16 \mathrm{ln}$. College Station: Alzheimer's Research \& therapy; 2019.

35. Fereshtehnejad SM, Damangir S, Cermakova P, Aarsland D, Eriksdotter M Religa D. Comorbidity profile in dementia with Lewy bodies versus Alzheimer's disease: a linkage study between the Swedish Dementia Registry and the Swedish National Patient Registry. Alzheimers Res Ther. 2014;6(5-8):65.

36. Froehlich TE, Bogardus ST Jr, Inouye SK. Dementia and race: are there differences between African Americans and Caucasians? J Am Geriatr Soc. 2001;49(4):477-84.

37. Glymour MM, Manly JJ. Lifecourse social conditions and racial and ethnic patterns of cognitive aging. Neuropsychol Rev. 2008;18(3):223-54.

38. RTI Press. Racial and ethnic disparities among individuals with Alzheimer's disease in the United States: A literature review. 2014.

39. Thomas K. Going Outside the Box: Identification of Active Diagnoses in the MDS 3.0. In: The Medical Care Blog; 2017. https://www.themedicalcareblog. com/going-outside-the-box-identification-of-active-diagnoses-in-the-mds-30/. Accessed 16 June 2021.

40. Saliba D, Buchanan J. Development \& Validation of a Revised Nursing Home Assessment Tool: MDS 3.0. Centers for Medicare \& Medicaid Services; 2008.

41. Morris JN, Howard EP, Steel K, et al. Updating the Cognitive Performance Scale. J Geriatr Psychiatry Neurol. 2016;29(1):47-55.

42. Paquay L, De Lepeleire J, Schoenmakers B, Ylieff M, Fontaine O, Buntinx F. Comparison of the diagnostic accuracy of the Cognitive Performance Scale (Minimum Data Set) and the Mini-Mental State Exam for the detection of cognitive impairment in nursing home residents. Int J Geriatr Psychiatry. 2007;22(4):286-93

\section{Publisher's Note}

Springer Nature remains neutral with regard to jurisdictional claims in published maps and institutional affiliations.

Ready to submit your research? Choose BMC and benefit from:

- fast, convenient online submission

- thorough peer review by experienced researchers in your field

- rapid publication on acceptance

- support for research data, including large and complex data types

- gold Open Access which fosters wider collaboration and increased citations

- maximum visibility for your research: over $100 \mathrm{M}$ website views per year

At $\mathrm{BMC}$, research is always in progress.

Learn more biomedcentral.com/submissions 